\title{
The reappearance hypothesis revisited: Recurrent involuntary memories after traumatic events and in everyday life
}

\author{
DORTHE BERNTSEN \\ University of Aarhus, Aarhus, Denmark \\ AND \\ DAVID C. RUBIN \\ Duke University, Durham, North Carolina
}

\begin{abstract}
Recurrent involuntary memories are autobiographical memories that come to mind with no preceding retrieval attempt and that are subjectively experienced as being repetitive. Clinically, they are classified as a symptom of posttraumatic stress disorder. The present work is the first to systematically examine recurrent involuntary memories outside clinical settings. Study 1 examines recurrent involuntary memories among survivors of the tsunami catastrophe in Southeast Asia in 2004. Study 2 examines recurrent involuntary memories in a large general population. Study 3 examines whether the contents of recurrent involuntary memories recorded in a diary study are duplicates of, or differ from, one another. We show that recurrent involuntary memories are not limited to clinical populations or to emotionally negative experiences; that they typically do not come to mind in a fixed and unchangeable form; and that they show the same pattern regarding accessibility as do autobiographical memories in general. We argue that recurrent involuntary memories after traumas and in everyday life can be explained in terms of general and well-established mechanisms of autobiographical memory.
\end{abstract}

Within the last 10 years, an increasing number of studies have examined characteristics of involuntary autobiographical memories - that is, memories of personal experiences that come to mind with no preceding retrieval attempts (e.g., Ball \& Little, 2006; Berntsen, 1996, 2001; Berntsen \& Hall, 2004; Berntsen \& Rubin, 2002; Kvavilashvili \& Mandler, 2004; Mace, 2007). Involuntary autobiographical memories in everyday life are more often about positive than negative events (e.g., Berntsen, 1996; Berntsen \& Hall, 2004; Berntsen \& Rubin, 2002), as is the case for autobiographical memory in general (e.g., Thompson, Skowronski, Larsen, \& Betz, 1996; Walker, Skowronski, \& Thompson, 2003). However, recurrent involuntary memories (i.e., involuntary autobiographical memories that people subjectively experience as being repetitive) have received almost no attention outside of clinical settings. Clinically, such memories are observed among people suffering from posttraumatic stress disorder (PTSD). The Diagnostic and Statistical Manual of Mental Disorders (DSM-IV-TR) definition of this disorder lists a number of reexperiencing symptoms, including "recurrent and intrusive distressing recollections" and "recurrent distressing dreams" of the traumatic event (American Psychiatric Association, 2000). Due to the lack of research in nonclinical populations, we have no data clarifying whether recurrent involuntary memories of au- tobiographical events are, in fact, tied to traumatic and/or negative emotional stress as argued in theories based on clinical observations (e.g., Ehlers, Hackmann, \& Michael, 2004; Horowitz, 1992).

Furthermore, a brief reflection on the very notion of recurrent memories should raise a number of questions. Exactly what is meant by the idea that a memory is recurrent? Does it mean that each recurrent memory is an exact copy of a previous memory of the same event or scene? This would seem to clash with the idea that memory is reconstructive (e.g., Bartlett, 1932). The debate over whether the act of remembering is a constructive creation of something new or an associative reactivation of stored and unchanging information has a long history in psychology. James (1890) argued strongly against the empiricist position that sensory impressions are stored in fixed forms and later reactivated through associations: "No state once gone can recur and be identical with what it was before" (p. 230). A similar position was taken by Bartlett and later by Neisser (1967), who found the idea of unchanging reactivations of the same stored material "so misguided - that it deserves a special name" (p. 281). To this end, he chose the term reappearance hypothesis (p. 281), which implies that "the same memory image, or other cognitive unit, can disappear and reappear over and over again" (p. 282). 
In contrast, many PTSD researchers argue that traumatic memories are able to involuntarily repeat themselves in consciousness in a fixed form, and that the particular repetitious nature of these memories derives from the stressful and/or traumatic nature of the material that they represent. Ehlers et al. (2004) offer several examples of this phenomenon-for example, a man who kept seeing headlights coming toward him because he had seen the same thing shortly before a car crash in which he was involved. Horowitz and Reidbord (1992) argued:

\section{"In general, the more a person experiences extreme terror during the event, the more likely the imagery of that event will be inscribed in the same sensory modalities of memory as perceptions. These memory inscriptions tend to return to conscious representa- tion in that same modality and, because of their viv- idness, tend to re-evoke the same emotions as the original experience." (p. 347)}

(For similar views, see Brewin, Dalgleish, \& Joseph, 1996; Ehlers \& Clark, 2000; Ehlers et al., 2004; Horowitz, 1992; van der Kolk \& Fisler, 1995.) These claims of reappearance are based on clinical observations and retrospective reports. Their validity therefore remains to be examined against recurrent involuntary memories recorded online in diary studies or comparable experimental evidence.

We address these questions in three studies. Because the phenomenon is understudied, we approach the key questions from different perspectives, involving different populations and a variety of methods. In Study 1, we examine the presence and content of recurrent involuntary memories as a function of danger and fear experienced at the time of the event among people with the same traumatic event in their relatively recent past; namely, the tsunami catastrophe in Southeast Asia in December 2004. Study 2 examines the frequency, emotional valence, and intensity of recurrent involuntary memories in a general population, in order to assess whether this phenomenon is limited to emotionally stressful and traumatic events, as assumed in clinical theories of PTSD. In Study 3, we examine whether the recurrent trauma memories are duplicates of previously recorded memories, as proposed in clinical theories of PTSD, or whether they differ from one another. In the following, we propose a theoretical framework for recurrent involuntary memories on the basis of well-established mechanisms of autobiographical memories in general, as an alternative to a theoretical framework on the basis of retrospective reports obtained from trauma victims in clinical settings. This framework allows us to generate hypotheses for our studies.

\section{An Autobiographical Memory Framework for Recurrent Involuntary Memories}

We use the term recurrent memories to refer to involuntary memories of autobiographical events that people subjectively experience as being repetitive. Whether or not these memories are actual copies of one another we treat as an empirical question. We study recurrent memories using two different strategies. Using a retrospective strategy, we ask participants to nominate their most recurrent memories in relation to a particular traumatic event (Study 1) or from their recent past (Study 2). Using a prospective strategy (Study 3), we ask participants to first nominate their most traumatic experience, after which they record involuntary memories in a structured diary study. They classify which of the recorded involuntary memories they experience as referring directly to their most traumatic event. Both strategies follow from our definition of recurrent involuntary memories as well as the definition used in the PTSD diagnosis (American Psychiatric Association, 2000).

The basic tenet of our theory is that recurrent involuntary memories occur when some autobiographical material has become highly accessible in memory. Since this may happen for a variety of events and for a variety of reasons, we assume that recurrent involuntary memories are relatively common experiences not limited to clinical populations or to emotionally negative events. Parsimoniously, we assume that the increased accessibility of material for recurrent involuntary memories is shaped by the same accessibility constraints as have been found for autobiographical memory in general. In a general sample of recurrent involuntary memories, we therefore predict a high frequency of recent events (Rubin \& Wenzel, 1996), emotionally intense (arousing) events (e.g., Dolcos, LaBar, \& Cabeza, 2004, 2005; McGaugh, 2003; Thompson et al., 1996), emotionally positive events (Walker et al., 2003), and positive events from young adulthood (Berntsen \& Rubin, 2002).

According to the present theory, recurrent involuntary memories occur when an autobiographical event satisfies several of these constraints at once. The more constraints it meets, and the better it meets them, the more likely it is to become a recurrent memory. A fresh traumatic event is a strong candidate, because it is both recent and highly emotional (see Berntsen, 1996, for a similar view). In addition, due to frequent rehearsal and life impact, it may become an enduring, highly accessible landmark event (e.g., Berntsen \& Rubin, 2006a; Pillemer, 1998). Also, accessibility may be further enhanced by active, conscious attempts at suppressing thoughts about the event, an effect which may involve standard rehearsal mechanisms (Wenzlaff \& Wegner, 2000). Thus, after a traumatic event, the predictions derived from our account are consistent with the PTSD diagnosis. The traumatic event is likely to come to mind repeatedly. People who were most emotionally aroused and closest to the danger at the time of the event will be more likely to suffer from recurrent memories than will people with less severe traumas. Within the event itself, the most emotionally arousing moments would be most likely to form recurrent memories. This latter point accords with many clinical theories of PTSD (e.g., Horowitz \& Reidbord, 1992; Pitman, 1988) and is consistent with the notion of tunnel memories (Christianson, 1992; Safer, Christianson, Autry, \& Österlund, 1998). However, outside trauma populations, recurrent memories will show the same characteristics as have been found for autobiographical memories in general. In short, we claim that recurrent memories are governed by the same constraints as are autobiographical memories in general, but that these constraints have negative effects after highly 
stressful events (for related views, see Berntsen, 1996, 2001; Berntsen \& Rubin, 2006a, 2007).

Because autobiographical memory records of the same event have been found to vary considerably over time when measured repeatedly within subjects (e.g., Anderson, Cohen, \& Taylor, 2000; Rubin, Schrauf, \& Greenberg, 2004), it is our assumption that many recurrent memories will not reinstate the same content, but will be recurrent in the sense of elaborating the same autobiographical event, while involving different details and perspectives. This is counter to theories based on clinical observations arguing that recurrent memories involve exact repetitions of previous recollections (e.g., Brewin et al., 1996; Ehlers \& Clark, 2000; Ehlers et al., 2004; Horowitz, 1992), but is consistent with a constructive view of autobiographical memory (e.g., Conway, 2005; Conway \& Pleydell-Pearce, 2000).

As is the case for involuntary autobiographical memories in general (Berntsen, 1996), we expect that recurrent memories are typically brought to mind by some cues in the surroundings or in thought. If such cues are highly specific, they may greatly constrain the construction of the memories. We assume that recurrent memories that appear to reinstate the same details will often arise in response to such highly specific and similar cues (see Brewin \& Holmes, 2003, for a similar view).

In the PTSD diagnosis (American Psychiatric Association, 2000) and trauma literature (e.g., Horowitz, 1992), recurrent memories and recurrent dreams are regarded as related phenomena that repeatedly activate the same problematic material. This claim has not been examined systematically. However, autobiographical memory generally favors recall of emotionally positive events (see Walker et al., 2003, for a review), whereas dreams, including recurrent dreams, have been found to be biased toward negative and problematic, often threatening material (see Revonsuo, 2000 , for a review). This might suggest that in nonclinical populations, recurrent dreams and recurrent autobiographical memories are in fact unrelated phenomena.

The autobiographical memory framework introduced here contradicts a long clinical tradition of linking recurrent involuntary memories with emotionally negative material. As Ehlers et al. (2004) summarize this view: "People do not usually have persistent intrusive memories of meetings. The crucial question remains why people with PTSD have persistent re-experiencing symptoms, and what aspects of trauma memories explain them" (p. 408). It also contradicts the related idea that recurrent memories reinstate unchangeable perceptual details of the original event (e.g., Ehlers et al., 2004; Horowitz \& Reidbord, 1992). Both ideas seem to refer back to the Freudian notion of repetition compulsion (Freud, 1914), especially as this notion was elaborated in relation to traumatic neuroses (Freud, 1919, 1920). Although Freud was more concerned with recurrent dreams than with recurrent memories, contemporary theories on recurrent trauma memories share his view that such recurrent material involves separate memory mechanisms that work markedly differently than normal autobiographical memory (e.g., Brewin et al., 1996; Ehlers \& Clark, 2000; Ehlers et al., 2004; Horowitz, 1992; van der Kolk \& Fisler, 1995). In the lack of a better term, we call such theories clinical theories in the following, because they view recurrent memories as a symptom of distress, and because they derive from clinical observations.

\section{STUDY 1}

We examine recurrent involuntary memories among individuals with the same traumatic event in their recent past-namely, the December 2004 tsunami catastrophe, which they experienced as tourists. In order to obtain conditions comparable to negative recurrent memories observed clinically, we use a clearly negative event and we ask for memories that people subjectively experience as recurrent, leaving unexplored in Study 1 whether the memories actually reinstate the same details, and whether recurrent memories in general are negative. The relatively uniform structure of the tsunami event allows segmentation into narrative categories whose frequencies can be examined as a function of how close the participants were to the tsunami.

We predict that people with recurrent memories of this traumatic event report higher levels of fear and danger experienced at the time of the event, as well as higher levels of current PTSD symptoms. We expect repeated memories to refer to the emotionally most arousing moments, for which reason the content of the recurrent memories will vary systematically with the location of the individual in relation to the wave.

\section{Method}

\section{Participants}

Participants were 118 Danes (60 women), mean age 45.9 years $(S D=13.4)$, age range $18-87$ years, who were tourists in Thailand or Sri Lanka at the time of the tsunami catastrophe on December 26, 2004. Material for the study was distributed through the travel agency My Travel. A total of 273 questionnaires were sent out to individuals above age 17. For ethical reasons, people who had suffered personal losses during their stay in East Asia were not contacted. The questionnaire was sent out in late October 2005, 10 months after the event. Fourteen incorrectly addressed questionnaires were returned by the postal service. Of the remaining 259,119 returned a questionnaire (yielding a response rate of $46 \%$ ). One questionnaire was mostly blank, and consequently was left out of the analyses.

\section{Questionnaire}

The questionnaire included the following questions related to demographics: age, gender, and country (whether the person had traveled in Sri Lanka or Thailand at the time of the tsunami). The following questions probed how close the person had been to the tsunami and whether he or she fulfilled the A1 and A2 trauma criteria (American Psychological Association, 1994):

Closeness. How close were you to the tsunami when it came? (1. I was directly threatened by the tsunami; 2 . I could see the tsunami, but I was not directly threatened by it; 3 . I heard about the tsunami, but did not see it myself.) The scale was reversed in the analyses.

$A 1$. Were you in life danger, and/or did you witness other people being in life danger (yes/no); were you injured, and/or did you witness other people being injured (yes/no)?

$A 2$. During the event, did you feel intense fear, helplessness, or horror (yes/no)?

To measure the impact of the traumatic event, the participants answered the 7-item Centrality of Event scale (CES; Berntsen \& Rubin, 2006a), the Posttraumatic Stress Disorder checklist (PCL; Blanchard, Jones-Alexander, Buckley, \& Forneris, 1996; Weathers, 
Litz, Huska, \& Keane, 1994), and they indicated whether they had made use of psychological counseling after they came home and, if so, for how many hours. The CES measures the extent to which a traumatic memory forms a central component of personal identity, a turning point in the life story, and a reference point for everyday inferences, rated on 5-point rating scales. The PCL is an inventory of the 17 PTSD symptoms for the DSM-IV-TR (2000) rated on 5-point scales. The participants were also asked whether the tsunami had had any positive impact on their lives by rating on a 5-point scale how much they agreed with the following claim: Seen in relation to the person I am today, I feel that my experience of the tsunami in spite of everything has had a positive influence on my attitude toward life $(1$ = strongly disagree $; 5=$ strongly agree $)$.

To assess the quality of their overall memory for the event, they rated the following four questions on 5-point Likert scales:

Vividness. How clear and vivid is your memory for your experience of the tsunami? $(1=$ extremely unclear $; 2=$ unclear $; 3=$ somewhat clear; $4=$ clear; $5=$ as clear as if it happened now.)

Coherence. When you recall the traumatic event, do you then recollect it as a coherent event or as disconnected fragments? $(1=$ totally incoherent $; 2$ = rather incoherent $3=$ somewhat coherent; $4=$ coherent $;$ = totally coherent.)

Rehearsal. How often have you talked with other people about your experience of the tsunami? $(1=$ never $; 2=$ seldom $; 3=$ sometimes; 4 = often; 5 = very often.)

Recurrent memories. Do you experience that memories for the same moment from the tsunami catastrophe pop into your mind again and again — and thus repeat themselves in consciousness ( yes/no)?

If they answered yes to the last question, they were asked to describe with their own words the memory for the moment that most frequently had repeated itself in their mind (roughly a third of the A4 page was left blank-ruled - to leave room for this description).

Frequency. If they had recurrent memories, they were also asked to estimate on a 4-point scale how often the most frequent recurrent memory had come to them $(1=$ several times a day; $2=$ several times a week; 3 = several times a month; 4 = several times during the year.)

Clearest memory. All participants were asked to describe the moment from their experience of the tsunami that they remembered most clearly today. We asked the last question to ensure that everyone could provide a memory and also to add more context for the interpretation of descriptions of recurrent memories. Participants were finally asked for permission to quote their memory descriptions.

The cover page of the questionnaire briefly explained that the purpose of the study was to examine people's experiences during the tsunami and the psychological consequences thereof. It was emphasized that participation was voluntary and that the responses were anonymous. It was also stated that the participants did not have to answer all questions if they found some of them intimidating or otherwise hard to answer. Only a few questions were left unanswered. However, not everyone provided an open-ended memory description. Also, people who had provided a description of a recurrent memory often did not also provide a description of a clearest memory. We had 124 different memory descriptions, of which 43 were descriptions of recurrent memories and 81 were descriptions of clearest memories.

\section{Scoring}

Emotion. A total of 124 memory descriptions were scored according to whether emotional valence was overall negative, overall positive, neutral $/$ mixed, or nonclassifiable. The scoring was done by two judges who were blind to whether the memory reports referred to "repeated" or "clearest" memories. They agreed in $87 \%$ of the cases. Disagreement was solved by discussion. Five reports $(4 \%)$ were scored as unclassifiable because too little information was present to decide on the emotional content of the report.

Narrative content. Descriptions of the recurrent memories were scored according to eight narrative categories. Each memory was scored for its most dominant content; thus, each memory record was seen as an instance of only one of the eight categories. The follow- ing is a brief description of each narrative category. Before the wave comes includes memory records that describe only the situation immediately before the wave hits the coast; such comments as "The sight of the water before the first wave came. The atmosphere on the beach and the feeling that something was wrong" (male, 42 years old). When the wave comes refers to the moment when the wave hits the beaches and the waterfront hotels; for example: "Wave number two begins in the sea and it rises like a wall that comes directly towards me and grabs everything on its way" (male, 44 years old). Escaping refers to the person trying to get away, for example by running, swimming, or sailing away from the wave. Escaping could also refer to witnessing other peoples' (successful or unsuccessful) attempts at escaping, but all cases actually classified as escaping involved descriptions of one's own escape, such as "When I ran away from the wave and when we sailed away from the island. We were seventeen people in a boat suitable for five or six" (female, 60 years old). Searching for loved ones refers to descriptions of actively searching for loved ones, either by searching in the environment, or by trying to reach people over the phone, not knowing if they had survived-for example, "Searching desperately for my 12-year-old daughter while walking in water to my hips in the flooded restaurant of the hotel" (female, 42 years old). A memory record was classified as an instance of Emotions if it primarily contained descriptions of emotional states and not much else-for example, "Fear and helplessness" (male, 50 years old). Destruction left by the wave refers to memory descriptions of the damage and devastation left by the tsunami after the sea had calmed down - for example, "Houses and stores in ruins, beaches and streets closed, many ambulances/helpless workers, I am walking mindlessly in the streets" (male, 53 years old). A memory record was classified as a worse case scenario if it described a bad situation that did not happen but might have happened, if the person had made a different choice - for example, "I am often thinking what would have happened if we had not left for Bangkok the day before" (male, 43 years old). Going home dealt with memories describing the trip back to Denmark and the arrival at home, such as "The tragic experience among the passengers in the evacuation plane" (male, 52 years old). An option of other was given for memory records that did not fit any of the above mentioned categories. However, this option was not used.

Two judges independently categorized the descriptions. They agreed in $91 \%$ of the cases. Disagreement was solved by discussion and by assessments of a third judge.

\section{Results}

In order to provide a background for evaluating the findings related to the recurrent memories, we first describe findings on severity of trauma and PTSD symptoms and their correlations in the total sample. We next compare participants with versus without recurrent memories on these measures. We finally examine the content of the recurrent memories.

\section{Severity of Trauma and PTSD Symptoms}

Sixty participants (51\%) confirmed the A1 criterion for the PTSD diagnosis that during the tsunami they had experienced or witnessed life danger or serious injury. Fiftyfive participants $(47 \%)$ confirmed the A2 criterion for the diagnosis that their response to the event had involved intense fear, helplessness, or horror. Thirty-eight (32\%) confirmed both the A1 and A2 criterion, thus satisfying the criteria for a traumatic event according to the $D S M$ $I V-T R$ (2000). Two participants (2\%) did not answer the PCL. Four participants (3\%) had left one or two items blank which we substituted by their mean of the answered items. The mean sum score for the PCL was 26.7 ( $S D=$ 
Table 1

Correlations Among PCL, CES, A1 Criterion, A2 Criterion, and Closeness to Wave

\begin{tabular}{llllll}
\hline & PCL & CES & A1 & A2 & A1\&A2 \\
\hline CES & $.65^{* * *}$ & & & & \\
A1 & $.32^{* *}$ & $.24^{*}$ & & & \\
A2 & $.45^{* * *}$ & $.51^{* * *}$ & $.32^{*}$ & & \\
A1\&A2 & $.46^{* * *}$ & $.48^{* * *}$ & $.67^{* * *}$ & $.72^{* * *}$ & \\
Closeness & $.41^{* * *}$ & $.35^{* *}$ & $.76^{* * *}$ & $.37^{* * *}$ & $.62^{* * *}$ \\
\hline
\end{tabular}

Note $-N=111$. PCL, Posttraumatic Stress Disorder checklist; CES, Centrality of Event scale; A1, PTSD diagnostic criterion concerning life danger and physical injury; A2, PTSD diagnostic criterion concerning fear, horror, and helplessness. $\quad{ }^{*} p<.01 .{ }^{* *} p<.001 . \quad{ }^{* * *} p<.0001$.

11.3, range 17-75). Eleven participants (9.5\%) had a PCL score at the critical level of 44 or more, which may be used as an indicator of PTSD (Blanchard et al., 1996). Gender differences were observed for the A 2 criterion, which was met by $60 \%$ of the women versus $34 \%$ of the men $\left[\chi^{2}(1)=7.90, p<.01\right]$ and the sum score for the CES [women, $M=22.56, S D=6.35$, vs. men, $M=19.32$, $S D=7.30, t(114)=2.55, p<.05]$.

Table 1 shows the correlations between the PCL, CES, the A criteria, and closeness to the wave. As in our previous work (e.g., Berntsen \& Rubin, 2006a, 2006b, 2007), substantial correlations are found between the PCL and CES. However, the correlations between the CES, PCL, and A criteria are generally higher here than in our previous work, which may reflect that the present participants answered the questionnaires on the basis of a more recent and more severe traumatic experience than had participants in our previous studies. Consistent with expectations, closeness to the wave was positively related to these standardized measures. In addition to the correlations reported in Table 1, the CES showed weak correlations with ratings of coherence $(r=-.20, N=117, p<.05)$, talked about $(r=$ $.20, N=117, p<.05)$, and positive meaning $(r=.24, N=$ $115, p<.05)$. Closeness was positively related to talked about $[r(115)=.26, p<.01]$ and $A 1 \& A 2$ correlated with vividness $[r(115)=.21, p<.05]$. No other correlations were observed between ratings of memory characteristics and the measures included in Table 1.

\section{Comparisons of Participants With and Without Recurrent Memories}

Forty-eight (41\%) participants indicated that they had recurrent memories. As shown in Table 2, systematic differences were found between participants with and without recurrent memories. The group with recurrent memories scored consistently higher on measures of severity of event, PTSD symptoms (including frequency of recurrent dreams about the event), as well as some measures on memory characteristics. A systematic relation was found between closeness to the wave and having recurrent memories. Among participants who reported that they had been directly threatened by the wave, $66 \%$ reported that they had recurrent memories. Among participants who had seen the wave but not been directly threatened by it, the percentage with recurrent memories was $45 \%$, whereas it was $19 \%$ among those who had only heard about the wave from a safe distance $\left[\chi^{2}(2)=19.01, p<.0001\right]$.
Analyses of memory content. Forty-three participants (90\% of participants with recurrent memories) provided a description of their most repetitious memory. All of the recurrent memory descriptions were scored as emotionally negative. The distribution of the eight narrative categories is shown in Table 3 . In the total sample, escaping is the most dominant category, followed by when the wave comes and searching for loved ones. However, as also illustrated in Table 3, the distribution of the categories differed systematically between the three groups of participants who had reported different levels of distance to the tsunami $\left[\chi^{2}(14)=36.29, p<.001\right]$. The best way of accounting for these different distributions seems to be that people had recurrent memories for whatever had been their emotionally most intense moments. As Table 3 shows, among those who reported that they had been directly threatened by the tsunami, the majority reported a recurrent memory about escaping, followed by searching for loved ones, which is likely to have been their most emotional moment. Among those who reported that they saw the wave without being directly threatened by it, the number of memories about escaping was reduced by a third compared with the former group, whereas four times more reported a recurrent memory of the moment when the wave hit the waterfront, which is likely to have been the most arousing moment for this group to the extent that they did not have to escape. Among those who heard about the tsunami from a safe distance, the most frequent narrative category was worse case scenario, a category absent from the other two groups. This category dealt with fictitious situations of danger prevented by some spontaneous decision to go someplace else on the day of the tsunami. For example, 1 participant who had not been near the wave envisioned running away from the wave with her husband and child, and the child falling (see Frankel, 1994, and Merckelbach, Muris, Horselenberg, \& Rassin, 1998, for similar findings).

Before the wave comes and when the wave comes are narrative categories of special interest in relation to the warning signal theory (Ehlers et al., 2002). A warning sig-

Table 2

Severity of Event, PTSD, and Memory Characteristics Among Participants With and Without Recurrent Memories of the Tsunami Catastrophe

\begin{tabular}{|c|c|c|c|c|c|}
\hline \multirow[b]{2}{*}{ Retrieval } & \multicolumn{2}{|c|}{ With } & \multicolumn{2}{|c|}{ Without } & \multirow[b]{2}{*}{$t / \chi^{2}$} \\
\hline & $M$ & $S D$ & $M$ & $S D$ & \\
\hline Proportion A1 & .73 & .45 & .35 & .48 & $16.47^{* * *}$ \\
\hline Proportion A2 & .60 & .50 & .38 & .49 & $5.39^{*}$ \\
\hline Proportion A1\&A2 & .49 & .51 & .20 & .41 & $10.56^{* *}$ \\
\hline Closeness & 2.34 & .79 & 1.63 & .79 & $4.74^{* * *}$ \\
\hline PCL score & 33.05 & 12.52 & 22.22 & 7.81 & $5.70^{* * *}$ \\
\hline CES score & 24.79 & 5.49 & 18.40 & 6.76 & $5.38^{* * *}$ \\
\hline Positive meaning & 3.40 & 1.01 & 3.51 & .88 & .63 \\
\hline Vividness & 4.35 & .67 & 4.10 & .75 & 1.87 \\
\hline Coherence & 3.90 & .93 & 3.91 & 1.03 & .09 \\
\hline Talked about & 4.08 & .71 & 3.49 & .92 & $3.75^{* *}$ \\
\hline
\end{tabular}

Note $-N=114-117$. PCL, Posttraumatic Stress Disorder checklist; CES, Centrality of Event scale; A1, PTSD diagnostic criterion concerning life danger and physical injury; A2, PTSD diagnostic criterion concerning fear, horror, and helplessness. ${ }^{*} p<.05 .{ }^{* *} p<.01 .{ }^{* * *} p<.0001$. 
Table 3

Frequencies (Percentages) of Narrative Categories As a Function of Whether the Participants Were Directly Threatened by the Tsunami, Saw the Tsunami, or Heard About the Tsunami From a Safe Distance

\begin{tabular}{|c|c|c|c|c|}
\hline & All & Threatened & Saw & Heard \\
\hline Category & $\overline{n=42^{*}}$ & $n=23$ & $n=11$ & $n=8$ \\
\hline Before the wave & 2.4 & 4.4 & 0.0 & 0.0 \\
\hline When the wave comes & 14.3 & 8.7 & 36.4 & 0.0 \\
\hline Escaping & 47.6 & 65.2 & 45.5 & 0.0 \\
\hline Searching for loved ones & 14.3 & 17.4 & 0.0 & 25.0 \\
\hline Emotions & 4.8 & 4.4 & 0.0 & 12.5 \\
\hline Destruction left by wave & 7.1 & 0.0 & 18.2 & 12.5 \\
\hline Worse case scenario & 7.1 & 0.0 & 0.0 & 37.5 \\
\hline Going home & 2.4 & 0.0 & 0.0 & 12.5 \\
\hline Other & 0.0 & 0.0 & 0.0 & 0.0 \\
\hline
\end{tabular}

*One person who did not indicate closeness to the wave is excluded.

nal is defined as "stimuli that were present immediately before the traumatic event happened or shortly before the moment that had the worst emotional impact" (Ehlers et al., 2002, p. 995). According to this theory, we should expect before the wave comes and when the wave comes to be especially frequent among those who felt directly threatened by the wave, because in those cases, these two narrative segments would most likely precede the worst moments. For those who reported seeing the wave without being directly threatened by it, the category before the wave comes should be especially pronounced for the same reason. An inspection of the frequencies in Table 3 shows that this is not the case. In fact, only one person in the entire sample reports a recurrent memory of the beach before the tsunami came. The frequencies in Table 3 do not rule out that a minority of recurrent memories may function as warning signals in the way described by Ehlers et al. (2002). However, the frequencies in Table 3 show that this explanation does not apply to the majority of the reported memories.

\section{Discussion}

The findings support predictions generated from the autobiographical memory framework described in the introduction as well as clinical theories of recurrent memories. People who reported recurrent memories of episodes from their tsunami experience also reported higher levels of PTSD symptoms and more severe exposure to the traumatic event. When the content of the most frequent recurrent memories were analyzed as a function of the participant's closeness to the tsunami, it appeared that the recurrent memories were generally about the most emotionally arousing moments. This agrees with expectations derived from the autobiographical memory framework as well as from some clinical theories of PTSD (e.g., Horowitz \& Reidbord, 1992; Pitman, 1988), but contradicts the warning signal hypothesis (Ehlers et al., 2002).

However, it is not clear whether the association between recurrent involuntary memories, on the one hand, and posttraumatic stress and negative affect, on the other hand, is particular to the specific population under study, or whether it can be replicated in a general population. We address this issue in Study 2.

\section{STUDY 2}

We examined the prevalence, emotion, and life span distribution of recurrent involuntary memories in a general population.

\section{Method}

Participants. A representative sample of 1,504 Danes, age range 18-96 years, participated. Table 4 shows the number and gender of respondents sorted into six age groups. Respondents were selected from all geographic areas of Denmark except Greenland and the Faroe Islands. All respondents were able to speak and understand Danish. In each household, 1 or 2 respondents were randomly selected via a combined criterion based on number of household members above age 16 and their birthdays.

Procedure. Data were collected as part of a telephone survey by TNS Gallup, Denmark. The response rate for the entire survey was $58.4 \%$. The questions of relevance for the present study were preceded only by demographic questions in the survey. The respondents were informed that the purpose of the present study was to obtain information about memories and dreams, and that no financial or political interests were involved. The questions are presented in Table 5. To ensure that our respondents based their answers on memories with an episodic quality, we asked for memories involving reliving and visual imagery. The Danish term for memories with such qualities roughly corresponds to the English term recollections. All six questions also included a "don't know" option, which was not read to the respondents, but only used if the respondent stated to the interviewer that he or she did not know the answer to the question. "Don't know" responses were coded as missing data. Only respondents who answered 3 to Question 1 were asked Questions $2-5$. The number of valid responses and "don't know" responses for Questions 1-6 were: (1) 1,461, 43; (2) 771, 22; (3) 769, 29; (4) 759, 34 ; (5) 718, 75; and (6) 1,472, 32.

\section{Results}

Frequencies of recurrent memories and dreams by age. Decade groupings were used to analyze the data by age of the respondents, as shown in Table 4. The over-60 grouping was used to ensure roughly equal numbers of respondents in each group, in which-although it has a large range-only $5 \%$ of the participants were above age 83 .

A large percentage of respondents had recurrent involuntary memories $(53 \%, S D=50 \%, S E=1 \%)$ and recurrent dreams $(29 \%, S D=45 \%, S E=1 \%)$ within the most recent year, although having recurrent memories was considerably more common than having recurrent dreams, as evidenced by a Cochran Q test $[Q(1)=197.7, N=$ $1,435, p<.0001]$.

Figure 1 shows the percentage of respondents reporting recurrent memories and recurrent dreams within the most recent year as a function of their age. There is

Table 4

Demographics and Percentage of Recurrent Memories by Age Group

\begin{tabular}{ccccc}
\hline Age Group & Mean Age & $n$ & \% Females & $\begin{array}{c}\text { \% Recurrent } \\
\text { Memories }\end{array}$ \\
\hline $18-29$ & 24 & 274 & 50.0 & 58.0 \\
$30-39$ & 34 & 319 & 54.9 & 56.7 \\
$40-49$ & 44 & 295 & 51.5 & 52.2 \\
$50-59$ & 55 & 275 & 58.5 & 52.2 \\
$60-96$ & 69 & 341 & 51.9 & 45.7 \\
\hline
\end{tabular}


Table 5

Questions for Study 2

1. (Answered by all): Do you experience that the same recollections recurrently pop into your mind by themselves - so that they repeat themselves in consciousness? We are not asking about dreams but about recollections that you experience when you are awake. $(1=$ I have never had such recurrent recollections; $2=$ I have had such recurrent recollections earlier in my life, but not within the most recent year; 3 = I have had such recurrent recollections within the most recent year.)

2. (If "3" to Q. 1): How often within the most recent year have you experienced that the same recollection (or the same recollections) has returned to your thoughts by itself? $(1=$ several times a day; $2=$ several times a week; $3=$ several times a month; 4 = several times a year; $5=$ only once.)

3. (If "3" to Q. 1): Think of the recollection that most frequently has returned to your thoughts by itself. Is this recollection emotionally very positive, positive, neutral, negative, or very negative? $(1=$ very positive $; 2=$ positive $; 3=$ neutral $; 4=$ negative 5 = very negative. $)^{*}$

4. (If "3" to Q. 1): Think of the recollection that most frequently has returned to your thoughts by itself. Is this recollection emotionally not at all intense, a little intense, somewhat intense, intense, or very intense? $(1=$ not at all intense; $2=a$ little intense; 3 = somewhat intense $; 4=$ intense $; 5=$ very intense.)

5. (If "3" to Q. 1): Think of the recollection that most frequently has returned to your thoughts by itself. How old were you in the event that this recollection is about? (years).

6. (Answered by all): Do you have particular dreams that repeat themselves? Hereby we mean for example dreams about the same scenes or the same particular themes. We are asking about dreams you have while sleeping — not daydreams while you are awake. ( 1 = I have never had such recurrent dreams; 2 =I have had such recurrent dreams earlier in my life, but not within the most recent year; 3 = I have had such recurrent dreams within the most recent year.)

${ }^{*}$ This scale was inverted in the analyses to have positive be higher than negative.

a slight decrease in recurrent involuntary memories and a more marked decrease in recurrent dreams with age $[F(4,1499)=2.99, p<.05$, and $F(4,1499)=9.95, p<$ .0001 , respectively]. The frequency measures of recurrent memories and recurrent dreams (Questions 1 and 6 in Table 5) showed a weak positive correlation $(\rho=.23$, $N=1,435, p<.0001$ ) also when controlling for age of the respondents in a partial correlation $[r(1,432)=.22$, $p<.0001]$.

Emotion and frequency of recurrent memories. The following analyses involve the 793 respondents who indicated that they had had recurrent memories in the last year. These respondents rated the valence of their most frequent recurrent memory $(M=3.46, S D=1.04$, $S E=.04)$, its emotional intensity $(M=3.23, S D=1.15$, $S E=.04)$, and how often it occurred $(M=3.11, S D=$ $0.99, S E=.04)$. Most of the recurrent memories were rated as positive $(45.4 \%)$ or as highly positive $(12.7 \%)$. Only a few memories were rated as negative $(15.2 \%)$ or highly negative $(4.7 \%)$. Neutral memories accounted for $22.0 \%$. The dominance of highly positive and positive over highly negative and negative memories was reliable $[Q(1)=144.1, N=600, p<.0001]$, with memories rated as neutral left out of the analysis. In a similar analysis based on intensity ratings, there was a dominance of memories rated intense $(25.7 \%)$ or highly intense $(16.1 \%)$, compared with memories rated mildly intense $(20.8 \%)$ or not at all intense $(6.9 \%)$, when memories rated somewhat intense $(30.6 \%)$ were left out of the analysis $[Q(1)=21.7$, $N=527, p<.0001]$. Thus, consistent with expectations derived from the autobiographical memory framework, recurrent involuntary memories generally show a dominance of emotionally positive memories, and more memories were rated high than low on emotional intensity.

Recurrent memories were rated as quite frequent. The frequency estimates were: several times a day (7.0\%), several times a week (19.8\%), several times a month (32.3\%), several times a year (37.1\%), and only once a year (3.8\%). These frequency estimates correlated weakly with rat- ings of the intensity of the memories $[r(667)=.19, p<$ $.0001]$; with the frequency scale reversed, but not with age of the memories or emotional valence $(p \mathrm{~s}>.1)$.

As shown in Figure 2, there were increases in valence and intensity over the life span, with no significant decrease in rated frequency of occurrence among those that had recurrent involuntary memories $[F(4,764)=5.13$, $p<.0005 ; F(4,754)=5.34, p<.0005$; and $F(4,766)=$ 1.10, n.s., respectively].

Recency and distribution across life. All respondents were at least 18 years old. Figure 3 plots the number of recurrent involuntary memories as a function of how long ago the event remembered occurred for memories rated as positive, neutral, or negative over the most recent 18-year period. The plots can be described as monotonically decreasing retention functions with no marked difference in the rate of loss over time as a function of valence, in that all three valences dropped to about one third of their initial 1-year level over 18 years. Thus, consistent with our predictions, a clear recency effect was found.

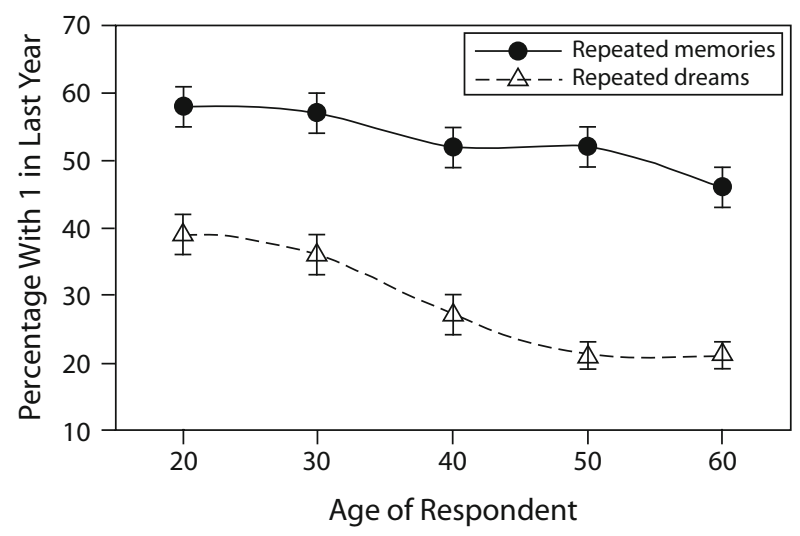

Figure 1. The percentage of participants with a repeated memory or dream in the last year as a function of the age of the participant. 


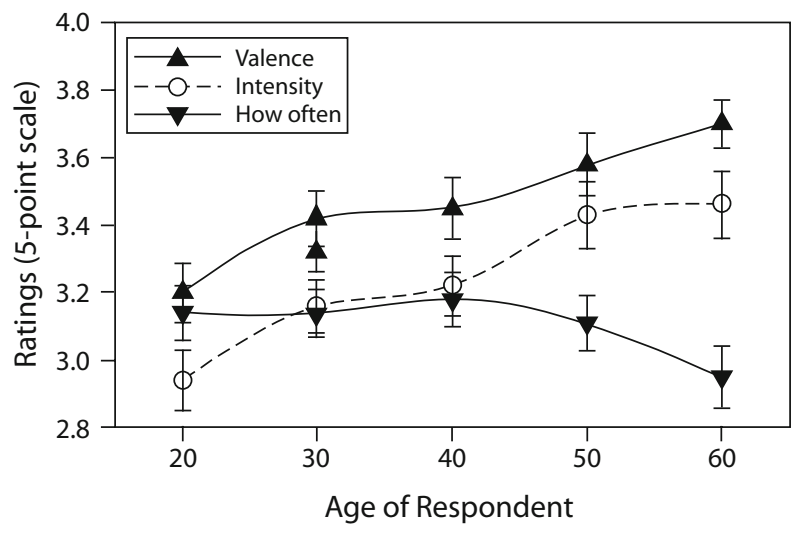

Figure 2. The mean ratings of valence, intensity, and frequency as a function of the age of the participant. $A$ higher value indicates a more positive valence, with a value of 3.0 being neutral.

Following Berntsen and Rubin (2002), we analyzed the distribution of memories over the life span-that is, as a function of respondents' age at the time of the remembered event. Because respondents in each of the groupings listed in Table 4 had, on average, lived through only half of the decade that designated their group, adjustments were made to that decade following our earlier work (Berntsen $\&$ Rubin, 2002). Respondents who were in the 20s group had $8 \%, 41 \%$, and $51 \%$ of their recurrent memories in the first three decades of life. Respondents who were in the 30s group had 9\%, 20\%, 32\%, and 39\% in the first four decades of life. In a manner similar to that illustrated in the findings shown in Figure 3, both groups showed a monotonic retention function, with more recent events producing the most recurrent involuntary memories.

In the three oldest groups, 405 respondents dated their recurrent involuntary memories, and 401 also indicated a valence. These 401 memories showed a different pattern. Their combined data is shown in Figure 4 as a function of valence. To produce this figure, we plotted the percent of positive, neutral, and negative memories in each decade shown in Figure 4, again adjusting for the decreasing number of responses in each decade. For the decades from 0 to 30, all 401 respondents could have provided responses, so we divided the number of responses in each valence and decade category by 401 . For the 40 s decade, the respondents in their 40s had only lived half of the decade, so we reduced their number by half and divided by 330 [i.e., $401-$ $(142 / 2)]$. For the 50s decade, none of the 40-year-old respondents were removed, but half of the 50-year-old respondents were, leaving a denominator of 194. As expected, the recurrent memories in this group showed a bump in young adulthood for positive memories, but not for negative and neutral memories. The findings illustrated in Figure 4 are similar to the life span distribution of positive, negative, and neutral involuntary autobiographical memories as illustrated in Figure 10 of Berntsen and Rubin (2002).

\section{Discussion}

Roughly half of the respondents reported that they had had recurrent involuntary memories within the most recent year. Frequency of respondents with recurrent memories from the last year decreased with increasing age of the respondents. This is consistent with previous findings for involuntary memories in general (Berntsen \& Rubin, 2002). Reports of recurrent dreams were less frequent, but showed a similar age-related pattern. Previous studies have found similar patterns concerning agerelated frequency of dream reports (see Funkhouser, Hirsbrunner, Cornu, \& Bahro, 1999, for a review).

The results supported our overall prediction that recurrent involuntary memories would show the same characteristics as autobiographical memories in general concerning emotion, recency, and life span distribution. The two-to-one dominance of positive relative to negative memories is similar to findings reported generally in autobiographical memory research (see Walker et al., 2003, for an overview). As expected, we found more memories referring to emotionally intense events than to events rated low in emotional intensity, and we found a high frequency of memories dealing with recent events. Ratings of (positive) valence and intensity increased with increasing age of the respondents. This can be seen to agree with findings showing that the experience of negative emotion becomes less frequent and less intense in old age (e.g., Charles, Reynolds, \& Gatz, 2001; Mroczek, 2001, for reviews). As in our previous work (Berntsen \& Rubin, 2002), for participants above age 40 , we found a bump in young adulthood for positive memories but not for negative and neutral memories. Thus, the content of the recurrent involuntary memories seems to have been formed by accessibility constraints that are well known from research on autobiographical memories in general. The findings therefore disagree with the view, found in clinical theories, that recurrent involuntary memories generally are a reaction to traumatic and/or emotionally negative experiences and that their occurrence requires specific memory systems or mechanisms.

\section{STUDY 3}

Studies 1 and 2 both used retrospective measures of recurrent involuntary memories, and therefore did not clarify

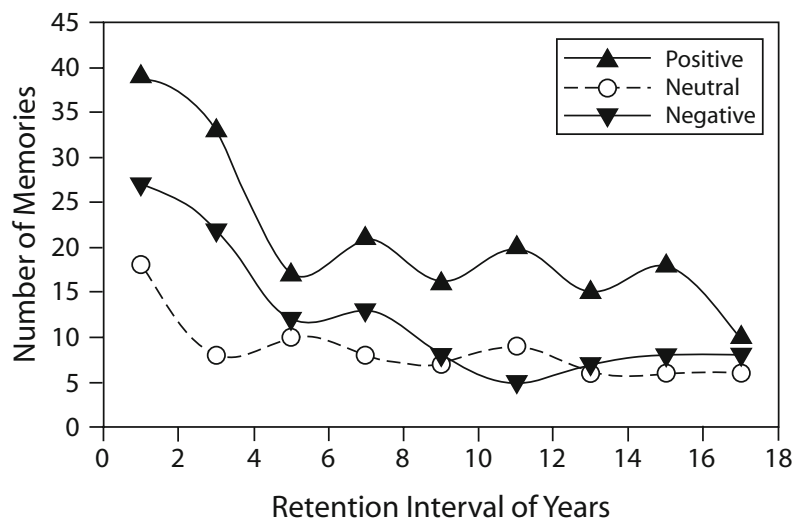

Figure 3. The retention function for positive, neutral, and negative repeated involuntary memories for all participants. 


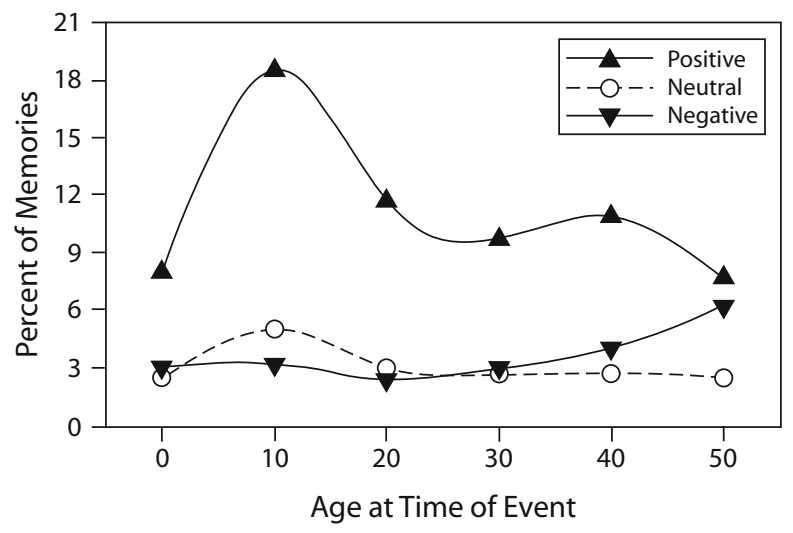

Figure 4. The distribution of positive, neutral, and negative repeated involuntary memories from age 0 to 50 for those participants who were 40 years old or older.

whether the recurrent memories reported by each individual deal with identical or different details of the traumatic event. Similar limitations characterize previously reported work (e.g., Hackmann, Ehlers, Speckens, \& Clark, 2004). This is a problem, because a memory may be experienced as "recurrent" for at least two different reasons. It may reinstate the exact same details as a previously recorded memory, or it may deal with different details, related to the same event as a previously recorded memory. In the first case, the same surface features of the memory are repeated. In the second case, the memories would differ at the surface level, but fit into the same narrative slot, by representing different parts of the same autobiographical event; for this reason, it may be interpreted by the person as being repetitive. Previous studies on recurrent involuntary memories (e.g., Hackmann et al., 2004) have used retrospective records and have therefore been unable to disentangle these different kinds of recurrent memories. Despite lack of evidence, clinical interpretations of this phenomenon (e.g., Brewin \& Holmes, 2003; Ehlers et al., 2004; Horowitz \& Reidbord, 1992) have focused on the first possibility of reinstating the same details, often ignoring the second possibility. One exception is Spence (1988), who stressed that even though recurrent memories may be experienced and retrospectively characterized as repetitious, they may in fact be part of a continuously changing series of recollections.

In order to disentangle these two possibilities, a prospective research strategy is used in Study 3. The participants nominated their most traumatic experience when filling in a PTSD questionnaire (Foa, 1995) a few weeks earlier. The participants then kept a structured involuntary memory diary (e.g., Berntsen, 2001) over a few weeks. For each involuntary memory record, they were asked whether it (1) referred directly to their most traumatic event; (2) was otherwise (e.g., thematically or causally) related to this event; or (3) was not related to the trauma. Category 1 is treated as recurrent trauma memories, because these records are classified by the participant as reinstating the traumatic event in memory.

\section{Method}

Study 3 involves data from a diary study of involuntary memories (Berntsen, 2001, Study 2) that have not been analyzed before. The participants recorded a total of 50 memories during an open-ended time period, with a maximum of 2 memories each day; thus, on any day they could record at most the first 2 memories that occurred involuntarily. On the basis of the autobiographical memory framework described in the introduction, we hypothesize that the majority of the recurrent trauma memories will not be exact duplicates of previously recorded trauma memories, but will instead address different aspects of the person's trauma, such as different time windows and/ or different details.

Participants. The study involved 9 participants ( 6 females, mean age, 25 years, age range, 19-33) who had participated in Berntsen (2001; Study 2), and who had recorded an involuntary memory of their traumatic event at least twice during the diary period. (Two people who had participated in Berntsen's [2001] study did not meet this criterion. A third person was excluded from the present study because she gave too few details to allow a content analysis of her recurrent trauma memories.) The mean age of the participants' traumatic memories was 2.3 years (range, 2 months -8 years). The traumatic events included assaults, life-threatening diseases, and death of a young friend. The participants met the formal diagnostic criteria for the PTSD as assessed by the Posttraumatic Stress Disorder checklist (PDS; Foa, 1995) in a screening conducted prior to the study (see Berntsen, 2001, for details on the instruction and procedure).

Scoring. The content of the recorded trauma memories was scored by two judges, who assessed for each participant whether the recorded memories referred to (1) the exact same moment as a previously recorded memory (i.e., it dealt with the same time slice and details as another memory recorded by the same participant) or (2) different moments from the same event course (i.e., it dealt with the same event but involved a different time slice and/or different details) or (3) the same internal, subjective state (e.g., mood state) as another memory record - that is, the memory records referred to the same inner feeling states with no or almost no information about the setting, details, and activities external to the person. Each memory record was classified as belonging to one of these categories. In addition, the judges assessed whether the memories had identical cues. In making this assessment, they took into account both the commonalities that the participant has endorsed as cues for the memory as well as the participant's description of the memory and the retrieval situation in which it came to mind. Only cues that showed a distinct and specific overlap were judged to be identical. The judges scored the memories independently after negotiating the scoring system in relation to 3 of the 29 memory records. There were no cases of disagreement.

\section{Results and Discussion}

As illustrated in Table 6, the great majority of the recurrent trauma memories referred to different time slices and/ or different details of the event. Thus, they were not duplicates of another memory, but represented different parts of the same trauma narrative. For example, 1 participant (Case 6) reported three memories of a particular occasion at which she had been physically assaulted by her former boyfriend. The first memory record dealt with "what it felt like in my face, how I tried to hide my face. How I had tried to get away." The second record dealt with "what he looked like on that day when he came home, how he smelled of beer and smoke." The third memory described her escape: "I was afraid and ran to my neighbour. I was afraid he would follow me. I was tense and looked out of the window to see if he was coming."

Table 6 shows that 2 participants deviated from this pattern by not recording memories that were "different details 
Table 6

Frequency of Memory Records by Characteristics of Content (Same or Differing) and by Characteristics of Cues

\begin{tabular}{cccccc}
\hline Case & $\begin{array}{c}\text { Records of } \\
\text { Trauma }\end{array}$ & $\begin{array}{c}\text { Same Time Slice } \\
\text { and Details }\end{array}$ & $\begin{array}{c}\text { Different Time } \\
\text { Slice and Details }\end{array}$ & $\begin{array}{c}\text { Same } \\
\text { Internal State }\end{array}$ & $\begin{array}{c}\text { Same } \\
\text { Cues }\end{array}$ \\
\hline 1 & 7 & 0 & $7(100 \%)$ & 0 & 0 \\
2 & 3 & $3(100 \%)$ & 0 & 0 & $3(100 \%)$ \\
3 & 3 & 0 & $3(100 \%)$ & 0 & 0 \\
4 & 2 & 0 & $2(100 \%)$ & 0 & 0 \\
5 & 2 & 0 & $2(100 \%)$ & 0 & 0 \\
6 & 3 & 0 & $3(100 \%)$ & 0 & 0 \\
7 & 2 & 0 & $2(100 \%)$ & 0 & 0 \\
8 & 4 & 0 & $4(100 \%)$ & 0 & 0 \\
9 & 3 & 0 & $1(33 \%)$ & $2(67 \%)$ & 0 \\
\hline
\end{tabular}

and different time slices." Case 9 recorded twice an almost identical memory of an emotionally painful internal state. These two memory records had almost no references to external characteristics of the situation. Only Case 2 recorded duplicate memories in which the setting and details were almost completely identical. All three memory records described a situation in which she was assaulted by a stranger when jogging by herself. All three records began with a description of the moment when she heard noises behind her, turned around and saw a man on the trail, realized that he was running faster than she was, for which reason she stepped aside to let him pass. The memory records ended with a description of the moment when the perpetrator (instead of passing her on the trail) attacked her from behind and got a stranglehold on her neck.

The fact that Case 2 reported an assault can hardly explain the consistency of her reports, since Cases 5, 6, and 7 also reported unique instances of assaults, happening at a particular time and place. Another more likely explanation has to do with the nature of the cues. As Table 6 shows, the memories of Case 2 are preceded by identical cues. All three memories came to mind when she was jogging by herself on an isolated nature trail, feeling a bit tense and suddenly seeing or hearing another person on the trail. Thus, the cues for the recurrent memories were very similar and also greatly overlapped with the content of the recurrent memories, which may have greatly constrained the reconstruction of the memories.

\section{GENERAL DISCUSSION}

Most clinical theories consider recurrent involuntary memories as reactions to highly stressful or traumatic experiences. Such memories are typically taken to reflect the operations of a special memory system (cf. Schacter, Wagner, \& Buckner, 2000), such as the Freudian unconscious (Freud, 1920), or an active memory storage with an inherent tendency toward repetition (Horowitz, 1992), or a memory system specific for memories that can be accessed only through nonverbal, situational cues (Brewin et al., 1996; Brewin \& Holmes, 2003). In contrast, we have presented evidence here showing that recurrent involuntary memories typically do not favor negative material, and that they can be explained with reference to general and wellestablished mechanisms of autobiographical memory.
In Study 1, participants with recurrent memories of the tsunami catastrophe reported higher levels of experienced fear and danger at the time of the event, as well as higher levels of current PTSD symptoms, than did participants without recurrent memories for the event. Moreover, the recurrent memories generally referred to the emotionally most arousing moments, in that the narrative content of the memories varied systematically with the location of the individual in relation to the wave. These findings were consistent with predictions derived from the general autobiographical memory framework as well as from clinical theories of PTSD, although the findings contradicted the warning signal thesis (Ehlers et al., 2004).

The findings from Study 1 could be explained in terms of an inherent tendency of intensely negative material to generate recurrent intrusions, as argued by clinical theories. Alternatively, they could be the result of general accessibility constraints for autobiographical memory favoring emotionally intense and recent material. Findings from Study 2 supported the latter interpretation by showing that recurrent involuntary memories in a general population have the same characteristics as other autobiographical memories regarding emotion, recency, and life span distribution. First, the recurrent involuntary memories in Study 2 showed the same two-to-one distribution of positive versus negative memories that has been found generally in autobiographical memory research (Walker et al., 2003). Second, in agreement with the intensity bias of autobiographical memory (e.g., Thompson et al., 1996), more recurrent memories were rated as high compared with low on a scale for emotional intensity. Third, a dominance of memories for recent events was found and, for respondents in their forties and older, a bump for positive, but not negative, memories was found, consistent with previous work (Berntsen \& Rubin, 2002; Rubin $\&$ Berntsen, 2003). In short, when recurrent involuntary memories were examined in a general population, they had the same characteristics as other autobiographical memories, suggesting that the most parsimonious explanation for findings in Study 1 is accessibility constraints related to autobiographical memory in general, and not mechanisms or memory systems specific to highly negative and/or traumatic events.

One limitation of Study 2 was the use of retrospective measures and the instructions to focus on the most fre- 
quent recurrent memory; this may have biased the results in favor of the most noteworthy recurrent memories. However, retrospective measures have similarly been used in the clinical research that Study 2 attempted to replicate. An advantage of Study 2 is that it measured involuntary recurrent memories in a general population with a range of different events. By providing data from a broader population with a wide range of events, Study 2 was able to correct the erroneous idea that recurrent involuntary memories are an aftermath of emotionally stressful experiences and should be explained in terms of mechanisms that pertain only to specific classes of stressful memories.

Findings from Study 3 further supported the validity of the general autobiographical memory framework for the understanding of recurrent memories. Consistent with the idea that memory is constructive, the findings showed that very few recurrent trauma memories were duplicates of previous memories. Despite being classified by the participants as recurrent records of the same traumatic event, the memories generally dealt with different time segments and details of this event. In the diary study from which the data for Study 3 derived (Berntsen, 2001), the participants were instructed to record only the first two involuntary memories that they may have had on a given day. It is therefore possible that duplicate memories of the traumatic event sometimes occurred without making it into the diary recording, because they came to mind after the maximum of two records had been reached. Nonetheless, the sample of recurrent trauma memories that was obtained by using a well-established recording procedure indicates that such duplicates are rare compared with the more variable kind of recurrent trauma memories.

Studies 1 and 2 showed only weak to moderate-sized correlations between having recurrent dreams and recurrent memories. The correlation was smallest in Study 2, suggesting that in a general population, the two phenomena are only weakly related.

\section{Conclusion}

The present work adds to an accumulating amount of research showing that characteristics of traumatic memories can be explained on the basis of general mechanisms of autobiographical memory (e.g., Berntsen, 2001; Berntsen \& Rubin, 2006a, 2007; Geraerts et al., 2007; Rubin, Feldman, \& Beckham, 2003; Talarico \& Rubin, 2003). Rather than attempting to explain aspects of traumatic remembering in terms of mechanisms that are limited to traumatic material, a more promising path is to extrapolate findings from general autobiographical memory research to account for traumatic memories in PTSD and related disorders. Here we have shown that one of the hallmarks of PTSD - recurrent involuntary memories - are also found in everyday life in response to neutral and positive experiences, and that recurrent trauma memories rarely reinstate the same sensory details, but more frequently represent the traumatic event from different temporal and thematic perspectives. An interesting avenue for future research is to use the structured diary method to examine recurrent involuntary memories that appear to be duplicates of previously recorded memories. We found a few examples of such memories here, all associated with highly specific and overlapping cue conditions. Future research should examine whether such a high degree of cue constraints is a general prerequisite for such memories as well as for their frequency and characteristics in everyday life. Here we have shown that the reappearance hypothesis in its current form in clinical theories finds little support when evaluated against empirical evidence.

\section{AUTHOR NOTE}

This work was supported by a grant from the Danish Research Council for Culture and Communication and by National Institute of Mental Health Grant R01 MH066079. The authors thank Torben Langermann and his colleagues at Spies, My Travel, for help with recruiting the participants for Study 1, and Helle Damkjær, Anne Stærk Jacobsen, and Line Bach Møller for assistance. Data for Study 2 were collected by Gallup, Denmark, TNS. Address correspondence regarding this article to D. Berntsen, Department of Psychology, University of Aarhus, Jens Chr. Skous Vej 4, 8000 Aarhus C., Denmark (e-mail: dorthe@psy.au.dk).

\section{REFERENCES}

American Psychiatric Association (2000). Diagnostic and statistical manual of mental disorders: DSM-IV-TR (4th ed., rev.). Washington, DC: Author.

Anderson, S. J., Cohen, G., \& TAYlor, S. (2000). Rewriting the past: Some factors affecting the variability of personal memories. Applied Cognitive Psychology, 14, 435-454.

BAll, C. T., \& LitTle, J. C. (2006). A comparison of involuntary autobiographical memory retrievals. Applied Cognitive Psychology, 20, 1167-1179.

Bartlett, F. C. (1932). Remembering: A study in experimental and social psychology. Cambridge: Cambridge University Press.

Berntsen, D. (1996). Involuntary autobiographical memories. Applied Cognitive Psychology, 10, 435-454.

BERnTSEn, D. (2001). Involuntary memories of emotional events. Do memories of traumas and extremely happy events differ? Applied Cognitive Psychology, 15, 135-158.

Berntsen, D., \& Hall, N. M. (2004). The episodic nature of involuntary autobiographical memories. Memory \& Cognition, 32, 789-803.

Berntsen, D., \& Rubin, D. C. (2002). Emotionally charged autobiographical memories across the lifespan: The recall of happy, sad, traumatic, and involuntary memories. Psychology \& Aging, 17, 636-652.

Berntsen, D., \& Rubin, D. C. (2006a). The centrality of event scale: A measure of integrating a trauma into one's identity and its relation to post-traumatic stress disorder symptoms. Behaviour Research \& Therapy, 44, 219-231.

Berntsen, D., \& Rubin, D. C. (2006b). Flashbulb memories and posttraumatic stress reactions across the life span: Age-related effects of the German occupation of Denmark during World War II. Psychology \& Aging, 21, 127-139.

Berntsen, D., \& RUBin, D. C. (2007). When a trauma becomes a key to identity: Enhanced integration of trauma memories predicts posttraumatic stress disorder symptoms. Applied Cognitive Psychology, 21, 417-431.

Blanchard, E. B., Jones-Alexander, J., Buckley, T. C., \& Forneris, C. A. (1996). Psychometric properties of the PTSD checklist (PCL). Behaviour Research \& Therapy, 34, 669-673.

Brewin, C. R., DAlgleish, T., \& Joseph, S. (1996). A dual representation theory of posttraumatic stress disorder. Psychological Review, 103, 670-686.

Brewin, C. R., \& Holmes, E. A. (2003). Psychological theories of posttraumatic stress disorder. Clinical Psychology Review, 23, 339-376.

Charles, S. T., Reynolds, C. A., \& Gatz, M. (2001). Age-related differences and change in positive and negative affect over 23 years. Journal of Personality \& Social Psychology, 80, 136-151.

Christianson, S.-Å. (1992). Emotional stress and eyewitness memory: A critical review. Psychological Bulletin, 112, 284-309.

Conway, M. A. (2005). Memory and the self. Journal of Memory \& Language, 53, 594-628. 
Conway, M. A., \& Pleydell-Pearce, C. W. (2000). The construction of autobiographical memory in the self-memory system. Psychological Review, 107, 261-288.

Dolcos, F., LABAR, K. S., \& CABEZA, R. (2004). Interaction between the amygdala and the medial temporal lobe memory system predicts better memory for emotional events. Neuron, 42, 855-863.

Dolcos, F., LaBar, K. S., \& Cabeza, R. (2005). Remembering one year later: Role of the amygdala and the medial temporal lobe memory system in retrieving emotional memories. Proceedings of the National Academy of Sciences, 102, 2626-2631.

Ehlers, A., \& ClARK, D. M. (2000). A cognitive model of posttraumatic stress disorder. Behaviour Research \& Therapy, 38, 319-345.

Ehlers, A., Hackmann, A., \& Michael, T. (2004). Intrusive reexperiencing in post-traumatic stress disorder: Phenomenology, theory, and therapy. Memory, 12, 403-415.

Ehlers, A., Hackmann, A., Steil, R., Clohessy, S., Wenninger, K., \& Winter, H. (2002). The nature of intrusive memories after trauma: The warning signal hypothesis. Behaviour Research \& Therapy, 40, 995-1002.

FoA, E. B. (1995). Posttraumatic Stress Diagnostic Scale (PDS). Minneapolis: National Computer Systems.

Frankel, F. H. (1994). The concept of flashback in historical perspective. International Journal of Clinical \& Experimental Hypnosis, 42, 321-336.

FreUd, S. (1914). Remembering, repeating and working-through. In J. Strachey (Ed.), The standard edition of the complete psychological works of Sigmund Freud (Vol. 12). London: Hogarth.

Freud, S. (1919). Introduction to "psycho-analysis and the war neurosis." In J. Strachey (Ed.), The standard edition of the complete psychological works of Sigmund Freud (Vol. 17). London: Hogarth.

FreUd, S. (1920). Beyond the pleasure principle. In J. Strachey (Ed.), The standard edition of the complete psychological works of Sigmund Freud (Vol. 18). London: Hogarth.

Funkhouser, A. T., Hirsbrunner, H. P., Cornu, C., \& Bahro, M. (1999). Dreams and dreaming among the elderly: An overview. Aging \& Mental Health, 3, 10-20.

Geraerts, E., Kozarić-Kovačić, D., Merckelbach, H., Peraica, T., Jelicic, M., \& CANDEL, I. (2007). Traumatic memories of veterans: Not so special after all. Consciousness \& Cognition, 16, 170-177.

Hackmann, A., Ehlers, A., Speckens, A., \& Clark, D. M. (2004). Characteristics and content of intrusive memories in PTSD and their changes with treatment. Journal of Traumatic Stress, 17, 231-240.

Horowitz, M. J. (1992). Stress response syndromes (2nd ed.). Northvale, NJ: Jason Aronson.

Horowitz, M. J., \& Reidbord, S. P. (1992). Memory, emotion, and response to trauma. In S.-Å. Christianson (Ed.), The handbook of emotion and memory: Research and theory (pp. 343-357). Hillsdale, NJ: Erlbaum.

JAMES, W. (1890). The principles of psychology (Vol. I). New York: Henry Holt \& Co.

Kvavilashvili, L., \& Mandler, G. (2004). Out of one's mind: A study of involuntary semantic memories. Cognitive Psychology, 48, 47-94.

MACE, J. H. (ED.) (2007). Involuntary memory. Malden, MA: Blackwell.

McGaUgh, J. L. (2003). Memory and emotion: The making of lasting memories. New York: Columbia University Press.
Merckelbach, H., Muris, P., Horselenberg, R., \& Rassin, E. (1998). Traumatic intrusions as "worse case scenario's." Behaviour Research \& Therapy, 36, 1075-1079.

MroczeK, D. K. (2001). Age and emotion in adulthood. Current Directions in Psychological Science, 10, 87-90.

NeIsSER, U. (1967). Cognitive psychology. East Norwalk, CT: AppletonCentury-Crofts.

Pillemer, D. B. (1998). Momentous events, vivid memories. Cambridge, MA: Harvard University Press.

Pitman, R. K. (1988). Post-traumatic stress disorder, conditioning, and network theory. Psychiatric Annals, 18, 182-189.

Revonsuo, A. (2000). The reinterpretation of dreams: An evolutionary hypothesis of the function of dreaming. Behavioral \& Brain Sciences, 23, 1083-1121.

Rubin, D. C., \& Berntsen, D. (2003). Life scripts help to maintain autobiographical memories of highly positive, but not highly negative, events. Memory \& Cognition, 31, 1-14.

Rubin, D. C., Feldman, M. E., \& Beckham, J. C. (2003). Reliving, emotions, and fragmentation in the autobiographical memories of veterans diagnosed with PTSD. Applied Cognitive Psychology, 18, 17-35.

Rubin, D. C., Schrauf, R. W., \& Greenberg, D. L. (2004). Stability in autobiographical memories. Memory, 12, 715-721.

Rubin, D. C., \& Wenzel, A. E. (1996). One hundred years of forgetting: A quantitative description of retention. Psychological Review, 103, 734-760.

Safer, M. A., Christianson, S.-Å., Autry, M. W., \& Österlund, K. (1998). Tunnel memory for traumatic events. Applied Cognitive Psychology, 12, 99-117.

Schacter, D. L., Wagner, A. D., \& Buckner, R. L. (2000). Memory systems of 1999. In E. Tulving \& F. I. M. Craik (Eds.), The Oxford handbook of memory (pp. 627-643). New York: Oxford University Press.

Spence, D. P. (1988). Passive remembering. In U. Neisser \& E. Winograd (Eds.), Remembering reconsidered: Ecological and traditional approaches to the study of memory (pp. 311-325). New York: Cambridge University Press.

Talarico, J. M., \& Rubin, D. C. (2003). Confidence, not consistency, characterizes flashbulb memories. Psychological Science, 14, 455-461.

Thompson, C. P., Skowronski, J. J., Larsen, S. F., \& Betz, A. L. (1996). Autobiographical memory: Remembering what and remembering when. Hillsdale, NJ: Erlbaum.

van Der KolK, B. A., \& Fisler, R. (1995). Dissociation and the fragmentary nature of traumatic memories: Overview and exploratory study. Journal of Traumatic Stress, 8, 505-525.

WALKer, W. R., Skowronski, J. J., \& Thompson, C. P. (2003). Life is pleasant-and memory helps to keep it that way! Review of General Psychology, 7, 203-210.

Weathers, F. W., Litz, B. T., Huska, J. A., \& Keane, T. M. (1994). The $P T S D$ checklist $(P C L)$. Unpublished scale available from the National Center for PTSD.

Wenzlaff, R. M., \& Wegner, D. M. (2000). Thought suppression. Annual Review of Psychology, 51, 51-91.

(Manuscript received February 19, 2007; revision accepted for publication August 20, 2007.) 